Available online on 30.10.2020 at http://jddtonline.info
Open Access to Pharmaceutical and Medical Research
unrestricted non-commercial use, provided the original work is properly cited

Open 1 Access

Research Article

\title{
In vitro antioxidant activity and gastroprotective effect of ethanolic extract from Cucumis melo L. var. inodorus fruit on ethanol-induced gastric ulcer in rats
}

\author{
Amel Bouaziz*, Assia Bentahar, Saliha Djidel, Saliha Dahamna and Seddik khennouf \\ Laboratory of Phytotherapy Applied to Chronic Diseases, Faculty of Nature and Life Sciences, University Ferhat Abbas Setif 1, Setif, 19000, \\ Algeria
}

\begin{abstract}
The aim of this study was to estimate the content of polyphenols, flavonoids and tannins and to evaluate the antioxidant property and the antiulcer activity of the ethanolic extract of melon (Cucumis melo L. var. inodorus) pulp on ethanol-induced gastric ulcers in rats. Ferric reducing power and hydroxyl radical scavenging tests were applied to evaluate the in vitro antioxidant activity. The polyphenolic and flavonoids contents of melon extract were found to be $56.5 \pm 2.49 \mathrm{mg} \mathrm{GAE} / \mathrm{g}$ of dry extract and $0.43 \pm 0.09 \mathrm{mg} \mathrm{QE} / \mathrm{g}$ of dry extract, respectively. Whereas the tannins content was $48.30 \pm 0.9 \mathrm{mg} \mathrm{ETA} / \mathrm{g}$ of dry extract. Melon pulp extract exhibited a good reducing potential with an $\mathrm{EC}_{50}$ of $4.23 \pm 0.08 \mathrm{mg} / \mathrm{ml}$ and high hydroxyl radical scavenging activity with $\mathrm{IC}_{50}$ of $1.83 \pm 0.09 \mathrm{mg} / \mathrm{ml}$. Oral administration of the melon pulp extract at doses of 200 and $600 \mathrm{mg} / \mathrm{kg}$ to rats reduced gastric mucosal lesions dose-dependently with percentage protection of 56.56 and $93.79 \%$ compared to omeprazole $(95.92 \%)$ as reference drug. These results showed that the melon pulp extract had a good antioxidant activity and gastroprotective potential suggesting it use as an adjuvant in the treatment of gastric ulcer.
\end{abstract}

Keywords: Cucumis melo var. inodorus, Polyphenols, Flavonoids, Tannins, Ulcer, Rat.

Article Info: Received 03 Sep 2020; $\quad$ Review Completed 12 Oct 2020; $\quad$ Accepted 21 Oct 2020; $\quad$ Available online 30 Oct 2020

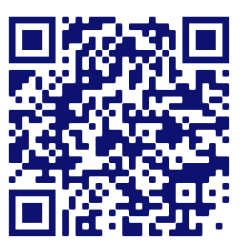

Cite this article as:

Bouaziz A, Bentahar A, Djidel S, Dahamna S, Khennouf S, In vitro antioxidant activity and gastroprotective effect of ethanolic extract from Cucumis melo L. var. inodorus fruit on ethanol-induced gastric ulcer in rats, Journal of Drug Delivery and Therapeutics. 2020; 10(5-s):302-307 http://dx.doi.org/10.22270/jddt.v10i5-s.4529

*Address for Correspondence:

Amel Bouaziz, Laboratory of Phytotherapy Applied to Chronic Diseases, Faculty of Nature and Life Sciences, University Ferhat Abbas Setif 1 , Setif, 19000, Algeria

\section{INTRODUCTION}

Gastric ulcer is an erosive lesions in the gastric mucosa characterized by a persistent inflammatory, oxidative and necrotic damage into stomach wall, which can perforate the submucosa and muscular layers and developed peritonitis or massive hemorrhage 1 . The pathophysiology of this disease has a multifactorial process that is caused by the imbalance between aggressive factors, as acid and pepsin and mucosal defense factors, especially blood flow and prostaglandins. In addition, the incidence of peptic ulcer can be increased by many factors including stress, alcohol consumption, smoking, Helicobacter pylori, and the use of nonsteroidal antiinflammatory drugs (NSAIDs) ${ }^{2}$. Several medications were used in the treatment of ulcers such as antibiotics, proton pump inhibitors, prostaglandin analogs, and $\mathrm{H} 2$ receptor blockers 3- 4. However, these agents are facing major problems due to their limited efficacy and severe side effects as gynecomastia, hypoacidity, impotence, osteoporotic bone fracture, hypergastrinaemia and cardiovascular disease risks 4-5. Oxidative stress is caused by reactive oxygen species (ROS) such as superoxide, hydrogen peroxide, hydroxyl, and nitric oxide (NO) radical. These ROS accumulations lead to damage to crucial biomolecules such as nucleic acids, lipids, proteins, polyunsaturated fatty acids, carbohydrates in living system. Antioxidants apparently protect the living system from this oxidative stress, which is a hallmark feature of cancer, cardiovascular disease, diabetes, and ulcer. Most of the natural plant antioxidants such as vitamin $\mathrm{C}$ and $\mathrm{E}$, carotenoids, polyphenols, flavonoids, and tannins have strong antioxidant capacity ${ }^{6}$ which play a vital role in the prevention and treatment of many diseases as gastric ulcer 7 . Therefore, new therapeutic alternatives that present a good effectiveness as well as safer therapies are needed for the improvement of ulcer healing and prevention of disease recurrence. Hence, efforts are headed towards the find of suitable treatment from natural product sources as fruits, vegetables and plant extracts which possess the 
antisecretory, cytoprotective and antioxidant property that play a key role in gastric mucosal protection 1.

Melon, which is also known as Cucumis melo L., belongs to the Cucurbitaceae family and it is one of the most widely cultivated and consumed fruits worldwide ${ }^{8}$. Various studies have reported that $C$. melo $\mathrm{L}$. is a delicious and juicy fruit offering numerous medicinal and nutritive functions. It contains polyphenols, organic acids, lignans and other polar compounds that are beneficial to human health ${ }^{9}$. Melon pulp is rich in important vitamins, phytoene, $\beta$-carotene, and 5 methyltetrahydrofolic acid and it possesses high antioxidant and anti-inflammatory properties ${ }^{8}$. However, there is little scientific data reported on the gastroprotective activity of $C$. melo. Hence, the current study was undertaken to evaluate the in vitro antioxidant activity and antiulcerogenic property of the ethanolic extract of $C$. melo L. var. inodorus pulp against ethanol induced ulcer model in rats.

\section{MATERIALS AND METHODS}

\section{Plant materials}

Fresh melon was purshed from the market in Setif region (Northeastern of Algeria). The whole fruit was washed, peeled and the pulp was separated from the flesh and then the rind was grated to reduce its size.

\section{Animals}

Male Wistar rats (150-200g) were purchased from Pasteur institute, Algiers. They were housed in an air-conditioned animal room (12 hours light/dark cycle, $23 \pm 2^{\circ} \mathrm{C}$ ) for one week for adaptation and have free excess to commercial diet and water ad- libitum.

\section{Extraction of phenolic compounds}

The extraction of phenolic compounds was carried out according to method used by Markham 10 . Briefly, $1 \mathrm{~kg}$ of crushed pulp was mixed with $5 \mathrm{~L}$ of ethanol-water mixture $(80: 20, v / v)$ and kept at room temperature for 5 days to allow maximum extraction of bioactive molecules. The resulting solution was then filtered and the supernatant was evaporated using vacuum rotary evaporator at $40^{\circ} \mathrm{C}$. The extract obtained was dried to obtain crude ethanolic extract and stored at $4{ }^{\circ} \mathrm{C}$ until use.

\section{Determination of total polyphenols content}

The total polyphenols content was determined by the FolinCiocalteu method as described by Li et al. 11 with slight modification. In brief, $0.1 \mathrm{ml}$ of pulp extract was mixed with $0.5 \mathrm{ml}$ of Folin-Ciocalteu reagent (diluted 10 times). After 4 min, $0.4 \mathrm{ml}$ of $7.5 \%$ sodium carbonate $\left(\mathrm{Na}_{2} \mathrm{CO}_{3}\right)$ solution was added. The final mixture was shaken and then incubated for 90 min in dark at room temperature. The absorbance of all samples was measured at $760 \mathrm{~nm}$ and the results are expressed in milligrams of gallic acid equivalents per gram dried weight (mg GAE/g DW).

\section{Determination of total flavonoids content}

The total flavonoids content of each extract was determined by a colorimetric method as described by Bahorun et al. ${ }^{12} .1$ $\mathrm{ml}$ of melon pulp extract was mixed with $1 \mathrm{ml}$ of aluminium chloride $\left(\mathrm{AlCl}_{3}\right)$ solution $(2 \%)$ and allowed to stand for 10 min. Absorbance of the mixture was then determined at 430 $n m$ versus prepared methanol blank. Results were expressed as quercetin equivalent per gram dried weight $(\mathrm{mg} \mathrm{QE} / \mathrm{g}$ DW).

\section{Determination of tannins content}

The capacity to precipitate haemoglobin was determined by using bovine fresh blood according to the method described by Gharzouli et al. ${ }^{13}$. Briefly, a volume of melon pulp extract was mixed with an equal volume of hemolysed bovine blood (absorbance $=1.6$ ). After $20 \mathrm{~min}$, the mixture was centrifuged at $4000 \mathrm{rpm}$ for $10 \mathrm{~min}$, and the absorbance of the supernatant was measured at $756 \mathrm{~nm}$. Results were expressed as mg equivalent tannic acid per gram dried weight (mg TAE/g DW).

\section{Evaluation of antioxidant activity}

\section{Ferric reducing power}

The reducing power of the melon pulp extract was determined according to the method of Chung et al. ${ }^{14}$. A 0.1 $\mathrm{ml}$ aliquot of different concentrations of extract or BHT was mixed with an equal volume of $0.2 \mathrm{~mol} / \mathrm{l}$ phosphate buffer (pH 6.6) and $1 \%$ potassium ferricyanide. The mixture was incubated at $50{ }^{\circ} \mathrm{C}$ for $20 \mathrm{~min}$ to reduce ferricyanide into ferrocyanide. After that, $0.25 \mathrm{ml}$ trichloroacetic acid was added into the mixture to stop the reaction, and the mixture was centrifuged at $3000 \mathrm{r} / \mathrm{min}$ for $10 \mathrm{~min}$. The supernatant $(0.25 \mathrm{ml})$ was added into distilled water $(0.25 \mathrm{ml})$ and $0.1 \%$ ferric chloride $(0.5 \mathrm{ml})$, and then the absorbance was measured at $700 \mathrm{~nm}$. The $\mathrm{EC}_{50}$ value was defined as the effective concentration of the extract or standard which had the absorbance of 0.5 .

\section{Hydroxyl radical scavenging assay}

Hydroxyl radical scavenging activity was measured by the ability of melon pulp extract to scavenge the hydroxyl radicals according to the method described by Smirnoff and Cumbes 15 with slight modifications. The reaction mixture consists of $100 \mu \mathrm{l}$ of varying concentration of samples or standard antioxidants, $1 \mathrm{ml}$ of $\mathrm{FeSO}_{4}(1.5 \mathrm{mM}), 0.7 \mathrm{ml}$ of $\mathrm{H}_{2} \mathrm{O}_{2}$ $(6 \mathrm{mM}), 0.3 \mathrm{ml}$ of sodium salicylate $(20 \mathrm{mM})$. This mixture was incubated at $37 \mathrm{C}^{\circ}$ for $1 \mathrm{~h}$, after which the absorbance of the hydroxylated salicylate complex was measured at 562 $\mathrm{nm}$. The percentage scavenging effect was calculated according to the following equation:

\section{Scavenging activity $(\%)=[$ A control - A sample $] /$ Acontrol× 100}

Where A control was the absorbance of the control (without sample) and A sample was the absorbance in the presence of the sample.

\section{Evaluation of antiulcer activity by ethanol-induced ulcer model}

The gastroprotective activity of melon pulp ethanolic extract was determined following the method used by Abdulla et al. 16 with slight modification. Rats were fasted for $24 \mathrm{~h}$ before the experiment but were allowed free access to drinking water till 1 hour before the experiment. The groups were divided follows; Group I served as control and received distilled water $(5 \mathrm{ml} / \mathrm{kg})$; Group II was treated with omeprazole (20 mg/kg) as reference drug; Groups III and IV were treated with 200 and $600 \mathrm{mg} / \mathrm{kg}$ of melon pulp extract, respectively. One hour after this pre-treatment, all the groups of rats received a dose of absolute ethanol $(2.5$ $\mathrm{ml} / \mathrm{kg}$ ) orally. The animals were sacrificed after $30 \mathrm{~min}$ of ulcerogen administration, and their stomach were removed, opened along the greater curvature, washed with cold saline, and then flattened stomach samples were photographed. The total area of the lesions and the total area of the stomach was measured using Image J software. The percentage of ulceration is calculated according to the following formula: 
$\%$ ulceration $=($ total ulcerated area $/$ total mucosal area) $\times 100$

Preventive Index (PI) was calculated for each treated group according to this formula:

$$
\% \mathrm{PI}=(\mathrm{Uc}-\mathrm{Ut}) / \mathrm{SUc} \times \mathbf{1 0 0}
$$

\section{Statistical analysis}

In vitro results were expressed as mean \pm standard deviation (SD) and the in vivo results were presented as mean \pm standard error of mean (S.E.M). The differences between groups were determined by analysis of variance (one-way ANOVA) followed by Dunnet's test. All results were analyzed using Graph Pad Prism version 5.00. Differences were considered significant at $\mathrm{p}<0.05$.

\section{RESULTS AND DISCUSSION}

\section{Total polyphenols, flavonoids and tannins contents}

Plant phenolic compounds are secondary metabolites with interesting properties for human health. The beneficial effects of these molecules are related to their antioxidant activity, particularly their ability to scavenge free radicals, to donate hydrogen atoms or electrons, or to chelate metal cations. Besides, phenolic compounds contribute largely to the color and sensory characteristics of fruits and vegetables 17. Therefore, it would be valuable to determine the amount of total phenolics present in the fruit extracts.

As seen in Table 1, the total phenolic and flavonoids contents in melon pulp ethanolic extract were found to be $56.5 \pm 2.49 \mathrm{mg} \mathrm{GAE} / \mathrm{g}$ and $0.43 \pm 0.09 \mathrm{mg} \mathrm{QE} / \mathrm{mg}$ extract. Whereas the tannins content was $48.3 \pm 0.9 \mathrm{mg} \mathrm{TAE} / \mathrm{mg}$ extract.

Table 1: Total polyphenols and flavonoids contents in melon pulp ethanolic extract

\begin{tabular}{|c|c|c|c|}
\hline Extract & $\begin{array}{c}\text { Total phenolic content } \\
\text { (mg GAE/g) }\end{array}$ & $\begin{array}{c}\text { Flavonoids content } \\
\text { (mg Q E/g) }\end{array}$ & $\begin{array}{c}\text { Tannins content } \\
\text { (mg TAE/g) }\end{array}$ \\
\hline ethanolic & $56.5 \pm 2.49$ & $0.43 \pm 0.09$ & $48.3 \pm 0.9$ \\
\hline
\end{tabular}

GAE : Gallic Acid Equivalent QE : Quercetin Equivalent TAE : Tannic Acid Equivalent. Results expressed as means \pm SD $(\mathrm{n}=3)$

The literature reports many studies comparing polyphenolic, flavonoid and tannin contents of different varieties of melon as $C$. melo var. reticulates and C. melo var. cantalupensis $9-18$ 19 , but polyphenolic, flavonoid and tannin contents of the variety $C$. melo var. inodorous were never assessed.

\section{Antioxidant activity evaluation}

\section{Ferric reducing power}

In reducing power assay, the yellow color of the test solution changes to various shades of green and blue, depending on the presence of reductants in the extract that might cause the reduction of the $\mathrm{Fe}^{3+}$ /ferricyanide complex to the ferrous form 20. Therefore, measuring the formation of Perl's Prussian blue at $700 \mathrm{~nm}$ can monitor the $\mathrm{Fe}^{2+}$ concentration.

In this study, it was observed that the reducing capacity of melon ethanolic extract and BHT increased dependently with increasing concentration. The melon ethanolic extract showed a good reducing power with $\mathrm{EC}_{50}$ of $4.23 \pm 0.08$ $\mathrm{mg} / \mathrm{ml}$; however, it remained significantly $(\mathrm{p}<0.001)$ lower compared to BHT (EC $50=0.05 \pm 0.006 \mathrm{mg} / \mathrm{ml}$ ) (Table 2).

Table 1: Antioxidant activities of melon pulp ethanolic extract

\begin{tabular}{|l|l|l|}
\hline \multirow{2}{*}{ Extract/standard } & EC $_{\mathbf{5 0}}(\mathbf{m g} / \mathbf{m l})$ & $\left.\mathbf{I C}_{\mathbf{5 0}} \mathbf{( m g} / \mathbf{m l}\right)$ \\
\cline { 2 - 3 } & Reducing power effect & Hydroxyl radical scavenging activity \\
\hline Ethanolic & $4.23 \pm 0.08^{* * *}$ & $1.83 \pm 0.09^{* * *}$ \\
\hline BHT & $0.05 \pm 0.006$ & $/$ \\
\hline Vitamin C & & $0.084 \pm 0.004$ \\
\hline
\end{tabular}

Results were expressed as mean $\pm \mathrm{SD}, \mathrm{n}=3 .{ }^{* * *} \mathrm{p}<0.001$, the comparison was realized against correspondent standards.

The reducing power of the extracts may provide a significant indication about the potential antioxidant capacity of the fruits and vegetables. The presence of antioxidants in the extract would result in the reduction of $\mathrm{Fe}^{3+}$ to $\mathrm{Fe}^{2+}$ by donating an electron 21 . C. melo var. inodorus pulp extract showed good reducing power indicating the compounds in this fruit, performing as good electron donors and therefore should be able to terminate radical chain reaction by converting free radicals and ROS into more stable products. Also, the reductive abilities of this extract may be attributed to the presence of polyphenols. Several studies have shown the correlations between reducing power and polyphenolic contents in the plant extracts 22-23-24.

\section{Hydroxyl radical scavenging activity}

Hydroxyl free radicals have been implicated in the etiology of much pathology and eventually resulted in the cell injury/death. Therefore, the scavenging of hydroxyl radicals by extracts may provide a significant protection to biomolecules against free radicals 25 .

As shown in Table 2, melon pulp ethanolic extract exibited good in vitro scavenging activity against hydroxyl radicals generated in a Fenton reaction system with $\mathrm{IC}_{50}$ of 1.83 
$\pm 0.09 \mathrm{mg} / \mathrm{ml}$, but this activity is relatively lower $(\mathrm{p}<0.001)$ compared to that of vitamin $\mathrm{C}$ as standard ( $\mathrm{IC}_{50}$ equal to $0.084 \pm 0.007 \mathrm{mg} / \mathrm{ml}$ ).

Hydroxyl radical is the major active oxygen species in the biological systems and it can cause lipid peroxidation and enormous biological damage ${ }^{26}$. In this study, melon pulp ethanolic extract displayed remarkable potential in scavenging hydroxyl radical which might be related to its amount of total phenolic and flavonoids content. According to many reports, there is a highly positive correlation between polyphenols, flavonoids, and antioxidant activities in many plant species, and this is mainly due to their redox properties, which allows them to act as reducing agents, hydrogen donors, and singlet oxygen quenchers ${ }^{21}$.

\section{Effect of melon pulp extract on ethanol-induced gastric lesions}

The etiology of peptic ulcer is mainly due to an imbalance between aggressive factors and the maintenance of mucosal integrity through the endogenous defense mechanisms. To regain this balance, different therapeutic agents are used to inhibit the gastric acid secretion or to increase the mucosal defense mechanisms by increasing mucus production or interfering with prostaglandin synthesis 27 . The present study investigated for the first time the antiulcer effect of ethanolic extract from C. melo var. inodorus pulp in experimental model of gastric ulcers induced by ethanol.

\section{Macroscopic evaluation of lesions}

As shown in Figure 1, the absolute ethanol administration induced extensive long and hemorrhagic gastric ulcers in the rats (Figure. $1 \mathrm{~A}$ ). Oral pretreatment with pulp melon ethanolic extract attenuated the number and the length of gastric lesions in a dose-depended manner (Figure. $1 \mathrm{~B}$ and C). Among the two tested doses, high dose of melon pulp extract $(600 \mathrm{mg} / \mathrm{kg})$ showed maximum inhibition on the number and length of gastric lesions. Omeprazole (20 $\mathrm{mg} / \mathrm{kg}$ ) (Figure. 1D) and pulp melon extract $(600 \mathrm{mg} / \mathrm{kg}$ ) had similar effects on the number and length of gastric ulcers and restore the normal appearance of the stomach. In addition, high dose of melon pulp extract $(600 \mathrm{mg} / \mathrm{kg})$ alone had no side effects on stomach.
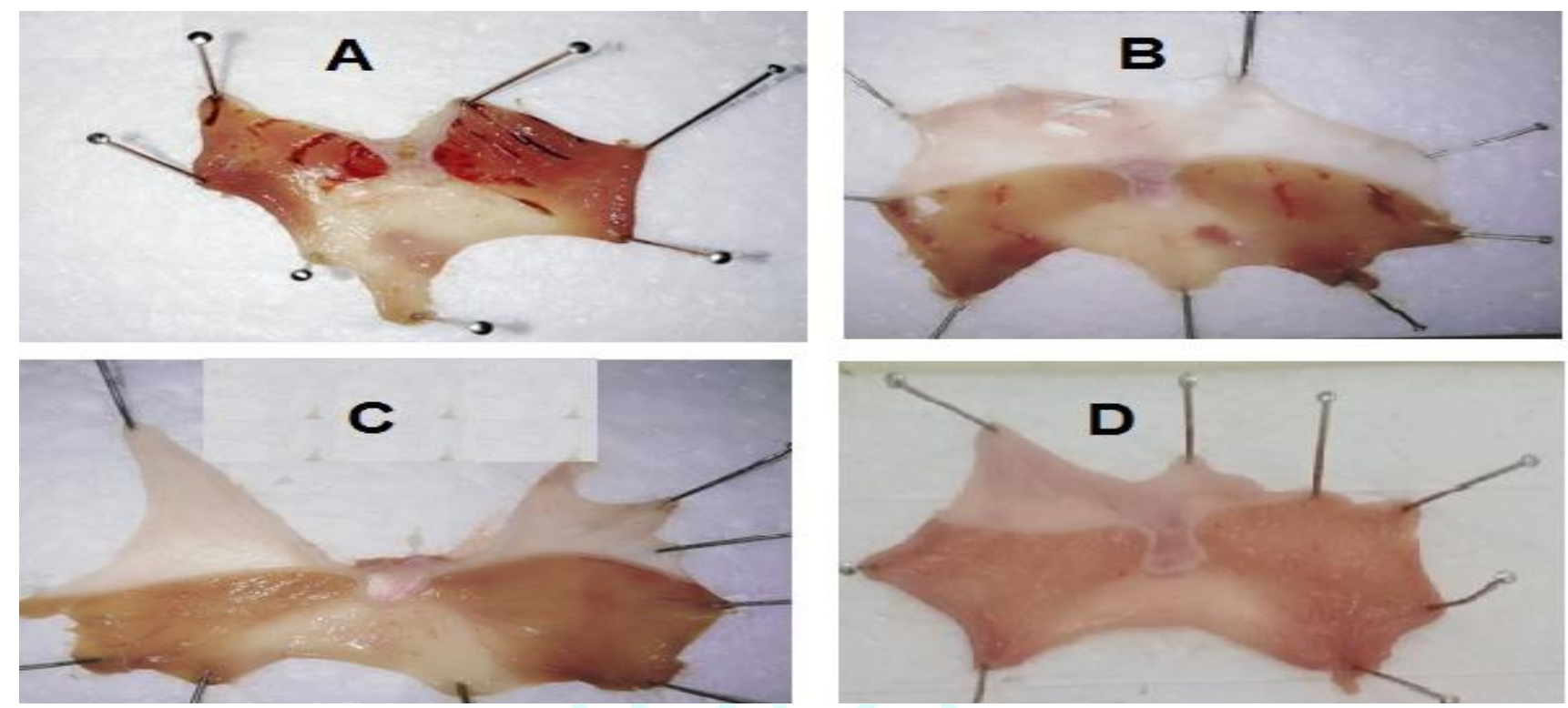

Figure 1: Macroscopic appearance of gastric ulcers induced by ethanol and protective effects of melon extract (200 and 600 $\mathrm{mg} / \mathrm{kg}$ ) and omeprazole. (A): Ethanol treated control; (B): Melon extract treated rat (200 mg/kg); (C), Melon extract treated rat $(600 \mathrm{mg} / \mathrm{kg}) ;(D):$ Omeprazole-treated rat $(20 \mathrm{mg} / \mathrm{kg})$.

\section{Evaluation of gastric protection}

Oral administration of melon pulp ethanolic extract (200 and $600 \mathrm{mg} / \mathrm{kg}$ ), one hour before the induction of gastric lesions with ethanol, significantly reduced lesion area with percentage of ulceration of $13.88 \pm 2.41$ and $1.98 \pm 0.63 \%$, respectively, compared to the control group $(31.96 \pm 2.41 \%)$ (Figure. $2 \mathrm{~A}$ ). Omeprazole $(20 \mathrm{mg} / \mathrm{kg}$ ) has been previously demonstrated to inhibit ethanol-induced gastric lesion formation and so it was used as positive control of lesion inhibition. Pretreatment of rats with omeprazole inhibited significantly $(\mathrm{p}<0.001)$ the gastric lesions to $1.98 \pm 0.63 \%$ (Figure. 2A). As shown also in Figure. 2B, the protective indexes of melon ethanolic pulp extract of the two doses 200 $\mathrm{mg} / \mathrm{kg}$ and $600 \mathrm{mg} / \mathrm{kg}$ groups were $56.56 \pm 2.43 \%, 93.79 \pm$ $1.98 \%$, respectively, while the reference drug, omeparazole $(20 \mathrm{mg} / \mathrm{kg})$ showed protection ratio of $95.92 \pm 1.98 \%$. This protective index was similar to that of $600 \mathrm{mg} / \mathrm{kg}$ treated rat group ( no significant difference). 
A

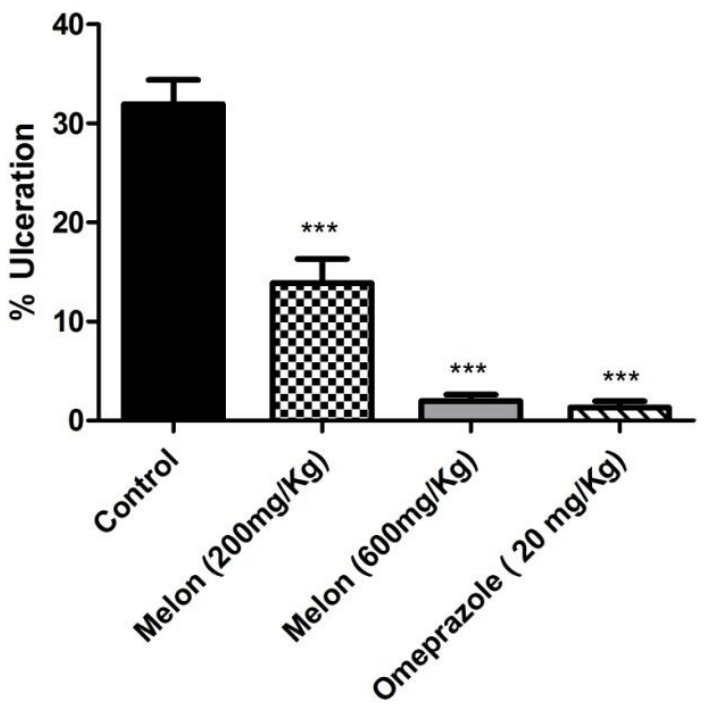

B

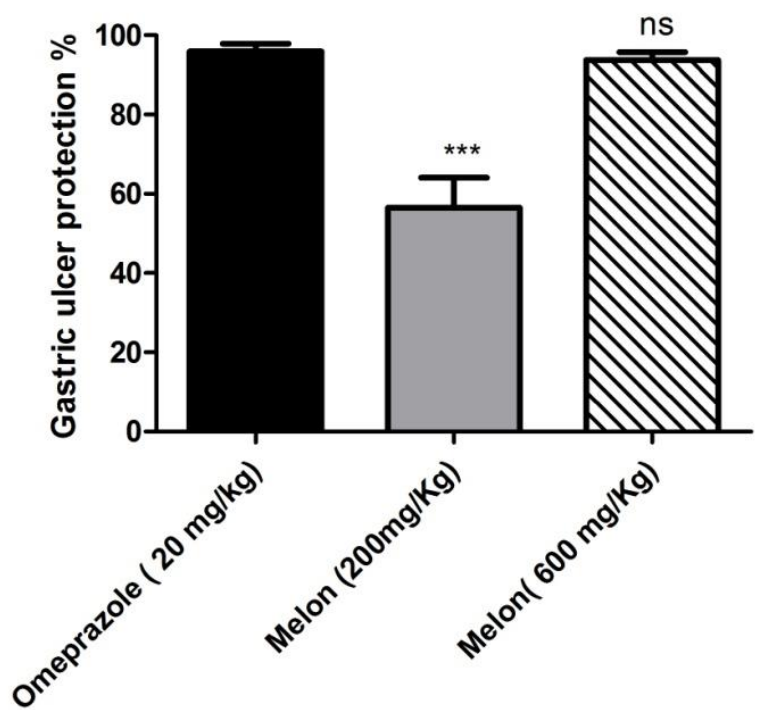

Figure 2: Effect of oral administration of melon ethanolic extract on gastric lesions induced by absolute ethanol in rats. (A): Ulceration expressed in \%. (B): Gastric ulcer protection index expressed in\%. Values are expressed as mean S.E.M. $(n=5)$; $\left({ }^{* * *} \mathrm{p}<0.001 ; \mathrm{ns} \mathrm{P}<0.05\right)$ compared to ulcerative control and omeprazole treated groups.

Ethanol-stimulated gastric lesions model have been used commonly to investigate the pathogenesis of gastric ulceration and to evaluate the gastroprotective effect of various drugs and natural products ${ }^{28}$. Ethanol is responsible for disturbances in gastric secretion, damage to the mucosa, alterations in the permeability, gastric mucus depletion, free radical production of superoxide anion and hydroperoxy free radicals, and ROS-mediated increased lipid peroxidation 29. Administration of ethanolic extract of C. melo var. inodorus (200 and $600 \mathrm{mg} / \mathrm{kg}$ ) exhibited gastoprotective effect against ethanol induced gastric damage which is may be due to its polyphenolic, flavonoids and tannins contents which are free radical scavengers as shown in the present study and are also known to possess antiulcer activity and prevent ethanol-induced gastric ulcer 30. Therefore, the presence of flavonoids and tannins in $C$. melo var. inodorus pulp may be associated with the ulcer preventing action. It is suggested that these active compounds would be able to stimulate mucous bicarbonate and to inhibit prostaglandin secretion and counteract with the liberating effect of reactive oxygen in the gastrointestinal lumen 17 whereas, tannins prevent ulcer development due to their protein precipitating and vasoconstricting effects. Their astringent action can help to precipitate microproteins on the ulcer site, thereby, forming an impervious layer over the lining, which hinders induced gastric ulcer ${ }^{31}$.

\section{CONCLUSION}

The results of this study showed that pulp ethanolic extract from C. melo var. inodorus has a high content of total phenolic compounds and exhibited good reducing potential and hydroxyl radical scavenging activity. Also, melon pulp ethanolic extract exerted appreciable gastroprotective effect against ethanol-induced gastric lesions in rats. However, more studies are needed to determine the exact mechanisms of antiulcer activity of melon pulp.

\section{ACKNOWLEDGEMENTS}

This work was supported by the Algerian Ministry of Higher Education and Scientific Research (MESRS), the Thematic Agency for Research in Health Sciences (ATRSS), and the General Directorate of Scientific Research and Technological Development (DGRSDT). We express our gratitude to these organizations.

\section{REFERENCES}

1. Sreeja PS, Arunachalam K, Saikumar S, Kasipandi M, Dhivya S, Murugan R, Parimelazhagan T, Gastroprotective effect and mode of action of methanol extract of Sphenodesme involucrata var. paniculata (C.B. Clarke) Munir (Lamiaceae) leaves on experimental gastric ulcer models. Biomedicine \& Pharmacotherapy, 2018; 9:1109-1118.

2. Karampour NS, Arzi A, Rezaie A, Pashmforoosh M, Kordi F , Gastroprotective effect of Zingerone on ethanol-induced gastric ulcers in rats. Medicina, 2019; 55:64 -72.

3. Massignani J J, Lemos M, Maistro E L, Schaphauser H P, Jorge R F, Sousa J P B, Bastos J K, De Andrade S F, Antiulcerogenic activity of the essential oil of Baccharis Dracunculifolia on different experimental models in rats. Phytother. Res., 2009; 23:1355-1360.

4. Zhou D, Yang Q, Tian T, Chang Y, Li Y, Duan LR, Li Y, Wang SW, Gastroprotective effect of gallic acid against ethanol-induced gastric ulcer in rats: Involvement of the Nrf2/HO-1 signaling and anti-apoptosis role, Biomedicine \& Pharmacotherapy, 2020; 126:110075-110084.

5. Kulikova OI , Stvolinsky SL, Migulin VA, Andreeva LA Nagaev I Y, Lopacheva OM, Kulichenkova KN, Lopachev AV, Trubitsina I E, Fedorova TN, A new derivative of acetylsalicylic acid and carnosine: synthesis, physical and chemical properties, biological activity, Daru , 2020; 28(1):119-130.

6. Tamboli F A and More H N. Evaluation of antiulcer and antioxidant activity of Barleria gibsoni Dalz. leaves. Pharmacognosy Res, 2016; 8(4):226-230.

7. Farzaei M H, Abdollahi M, Rahimi R, Role of dietary polyphenols in the management of peptic ulcer, 2015; 21(21):6499-6517. 
8. Bouaziz A, Djidel S, Bentaher A, khennouf S. Polyphenolic content, Antioxidant and Anti-inflammatory activities of Melon (Cucumis Melo L. var. inodorus) Seeds. Journal of Drug Delivery and Therapeutics, 2020; 10(2-S):22-26.

9. Qian O Y, Harith S, shahril MR, shahidan N. Bioactive compounds in cucumis melo L. and its beneficial health effects: a scoping review. Malays. Appl. Biol., 2019; 48(4):1-13.

10. Markham K R. Techniques of Flavonoid Identification, London Academic Press, Chap. 1 and 2, 1982, p. 113.

11. Li HB, Cheng KW, Wong CC, Fan KW, Chen F, Jiang Y, Evaluation of antioxidant capacity and total phenolic content of different fractions of selected microalgae, Food chem,2007; 102:771-776.

12. Bahorun T, Gressier B, Trotin F, Brunet C, Dine T, Luyckx, Oxygen species scavenging activity of phenolic extracts from hawthorn fresh plant organs and pharmaceutical preparations. Arzneimittel forschung, 1996; 46:1086-1089.

13. Gharzouli K, Khennouf S, Amira S, Gharzouli A, Effects of aqueous extracts from Quercus ilex L. root bark, Punica granatum L. fruit peel and Artemisia herba-alba Asso leaves on ethanol-induced gastric damage in rats. Phytother Res, 1999; 13:42-45.

14. Chung YC, Chen SJ, Hsu CK, Chang CT, Chou ST, Studies on the antioxidative activity of Graptopetalum paraguayense. Walther. Food Chem, 2005; 91:419-424.

15. Smirnoff N, Cumbes QJ, Hydroxyl radical scavenging activity of compatible solutes. J Phytochemestry, 1989; 28: 1057 -1060

16. Abdulla MA, Ahmed KAA, Al Bayaty FH, Masood Y. Gastroprotective effect of Phyllanthus niruri leaf extract against ethanol-induced gastric mucosal injury in rats. Afr J Pharma Pharmacol, 2010; 4:226 -630.

17. Nagulsamy $\mathrm{P}$, Ponnusamy $\mathrm{R}$, Thangaraj $\mathrm{P}$, Evaluation of antioxidant, anti-inflammatory, and antiulcer properties of Vaccinium leschenaultia Wight: A therapeutic supplement. Journal of food and drug analysis, 2015; 3:376 -386.

18. Vella FM , Cautela D, Laratta B, Characterization of polyphenolic compounds in cantaloupe melon by-products. Foods, 2019; 8: 196 -204

19. Ezzat S M, Raslan M, Salama M M, Menze E T, Hawary S, In vivo anti-inflammatory activity and UPLC-MS/MS profiling of the peels and pulps of Cucumis melo var. cantalupensis and Cucumis melo var. reticulates . Journal of Ethnopharmacology, 2019; 237:245-254.

20. Djenidi H, Khennouf S, Bouaziz A, Antioxidant activity and phenolic content of commonly consumed fruits and vegetables in Algeria. Progress in Nutrition, 2020; 22(1):224235.

21. Bouaziz A, Khennouf S, Abu zarga M, Abdalla S, Baghiani A, Charef N, Phytochemical analysis, hypotensive effect and antioxidant properties of Myrtus communis L. growing in Algeria. Asian Pac J Trop Biomed., 2015; 5:19-28.

22. Bentahar A, Khennouf S, Bouaziz A, Baghiani A, Dahamna S, Amira S, Arrar L , Polyphenols content and antioxidant activities of selected Algerian plants used for gastroduodenal ulcers. Der Pharma Chemica, 2016; 8(12):88-99.

23. Djidel S, Bouaziz A, Khennouf S, Bentahar A, Baghiani A Dahamna S, Amira S, Effect of methanol extract prepared from leaf of Pistacia lentiscus on plasma antioxidant activity and biomarkers of oxidative stress in liver tissue of healthy rats. Annual research and review in biology, 2018; 23(4):110.

24. Saoudi S, Khennouf S, Mayouf N, Amira S, Dahamna S, Hosni $\mathrm{K}$, Phytochemical Screening and in vivo and in vitro evaluation of antioxidant capacity of Fargaria ananassa, Prunus armeniaca and Prunus persica fruits growing in Algeria. Progress in Nutrition, 2020; 22(1):236-252.

25. Bouaziz A, Khennouf S, Abu Zarga M, Abdalla S, In vitro antioxidant, hypotensive and diuretic activities of Origanum glandulosum in rat. Bangladesh J Pharmacol, 2019; 14:17-25.

26. Rahman $M$, Badrul Islam B, Biswas $M$ and Khurshid A H M, In vitro antioxidant and free radical scavenging activity of different parts of Tabebuia pallidagrowing in Bangladesh. BMC Research Notes, 2015; 8:2-9.

27. Srividya L and Reddy RN, Evaluation of anti-ulcer activity of ethanolic extract of seeds of Hordeum vulgare in rats. European Journal of Biomedical and Pharmaceutical Sciences, 20, 4(3):272-277.

28. Simões S, Lopes R, Campos M C D , Marruz M J, da Cruz M EM , Corvo L, Animal models of acute gastric mucosal injury: macroscopic and microscopic evaluation, Animal Model Exp. Med., 2019; 2(2):121-126.

29. Maheswari B, Devi PR, Ajith K, VedPrakash P, SeshaSai Gayatri K, Evaluation of antiulcer activity of ethanol extract of leaves of Lactuca sativa. Journal of Drug Delivery \& Therapeutics, 2020; 10(4):196-199.

30. Sumbul S, Mohd. Aftab Ahmad, A, and Moh L, Role of phenolic compounds in peptic ulcer: An overview. J Pharm Bioallied Sci, 2011; 3(3):361-367.

31. Al-Rehaily A J, Al-Howiriny TA, Al-Sohaiban MO, Rafatullah S, Gastroprotective effects of Emblica officinalis on in vivo test models in rats. Phytomedicine, 2002; 9:515-22. 